\title{
His bundle haemorrhage and external cardiac massage: histopathological findings
}

\section{ROSSI, L MATTURRI}

From the Department of Pathology, Laboratory of Cardiovascular Research, University of Milan, Milan, Italy

SUMMARY Histological examination showed acute haemorrhage of the bifurcating His bundle and of the left bundle branch in a 35 year old man who died after being given external cardiac massage for cardiac arrest. "Hammering" of the ventricular septum crest against the central fibrous skeleton of the heart by compression of the sternum was believed to have caused the haematoma of the junctional tissue.

There is a risk of injury to the heart during external cardiac massage. ${ }^{1}$ Cardiac rupture (particularly of the right atrium), and epicardial, endocardial, and/or

Requests for reprints to Dr L Rossi, Via Annunciata 23/4, 20121 Milan, Italy. intramyocardial haemorrhage have been reported, ${ }^{1}$ as a consequence of the pressures that must be applied during this emergency manoeuvre ${ }^{2}$ (fig 1). But the possibility of lesions of the specialised junctional tissue has not been investigated.

We report the histopathological findings in the

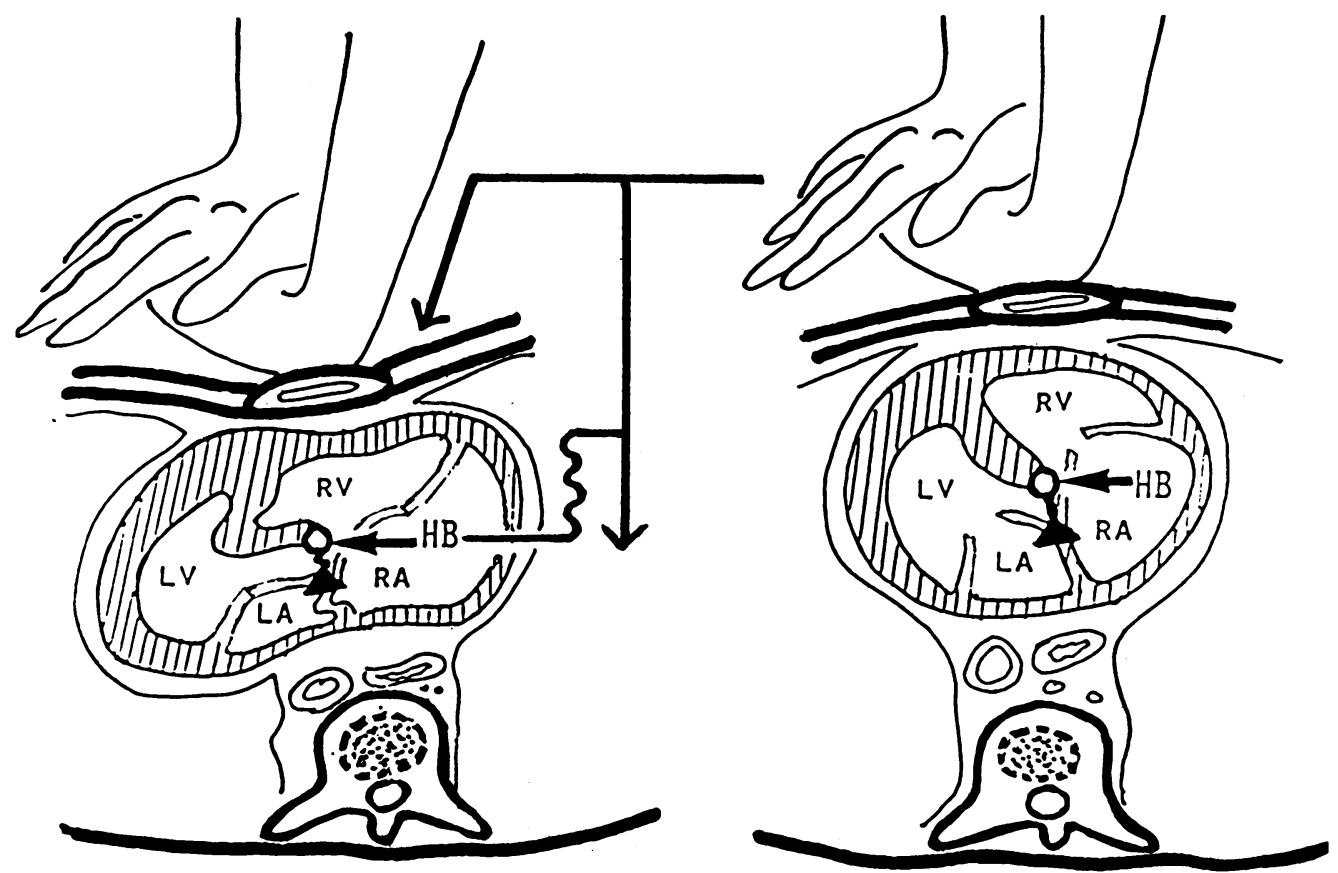

Fig 1 The mechanics of external cardiac massage. The ventricular septum is in parallel with the axis of sternal compression (left) and relaxation (right) and is crushed repeatedly, thereby hammering the bifurcating His bundle against the heart's fibrous skeleton (black triangle). HB, His bundle; LA and LV, left atrium and ventricle; $R A$ and $R V$, right atrium and ventricle. 


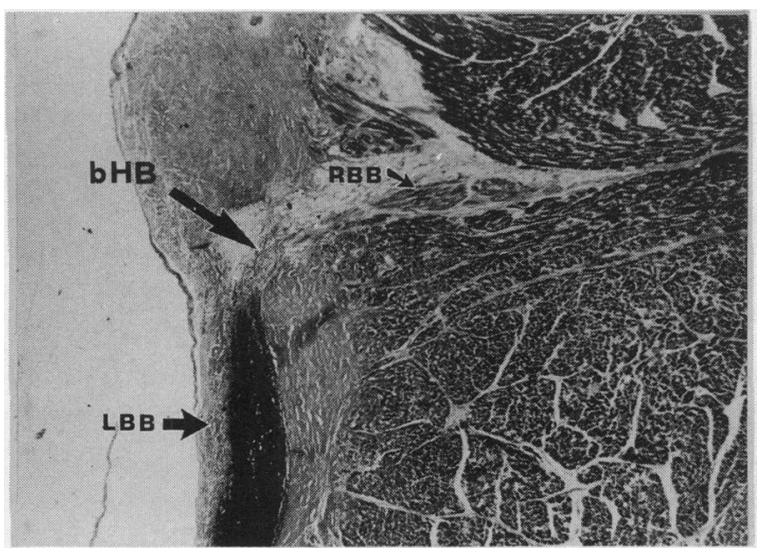

Fig 2 Haematoma of the proximal left bundle branch, from the hisian bifurcation downwards; the root of the right bundle branch is intramural. Azan stain, original magnification $\times$ 25. bHB, bifurcating His bundle; $L B B$ and $R B B$, left and right bundle branch.

conduction system of a patient who did not survive cardiac arrest, despite correctly applied closed chest cardiac massage.

\section{Case report}

A 35 year old man, with no history of heart disease suddenly presented with life-threatening shock; resuscitation attempts, including external cardiac massage, were continued until the patient died of a cardiac arrest. At necropsy an acute anterolateral myocardial infarction was found. Histological examination of the conduction system ${ }^{3}$ showed a recent subendocardial septal haematoma of the proximal left bundle branch and the hisian bifurcation; the root of the right bundle branch was intramural (fig 2).

\section{Discussion}

Did the His bundle haemorrhage occur during life or immediately after death? Efforts at emergency resus- citation usually continue until after the patient has died. Because reliable electrocardiograms cannot be obtained during cardiac massage the exact time of death cannot be determined. Moreover, raised intracranial pressure and hypoxia can ccuse spotty haemorrhagic effusions in the heart of people who die of cardiorespiratory arrest, particularly those on anticoagulants.

None the less, whatever other factors may have been responsible for findings in other cases, we believe that in our patient the junctional haematoma was caused by injury during attempted resuscitation.

During classic closed chest cardiac massage (fig 1) the heart is squeezed between the sternum and the spinal column; considerable pressure must be applied by the operator to achieve adequate pumping of the ventricular chambers. Ejection of blood usually provides some compliance to protect the free walls of the ventricles from injury. But the stiff ventricular septum, which lies along the axis of the piston action, is crushed and bent during each sternal compression (fig 1); in particular, the bifurcation of the His bundle, which straddles the septal crest, is hammered against the anvil of the central cardiac skeleton (fibrous body/aortoventricular membrane ${ }^{4}$ ). Because it is the target of heavy, repeated impacts this site is at increased risk of traumatic bleeding (fig 2).

We are not questioning the rationale of closedchest massage; however, we believe that whenever the heart is crushed by accident or during resuscitation, the potential effect on the conduction system must be remembered.

\section{References}

1 Bloor CM. Cardiac pathology. Philadelphia: Lippincott, 1978:376-7.

2 American Heart Association. Heartsaver technique teaching guide. Dallas, 1978:31-4.

3 Rossi L. Histopathology of arrhythmias. Philadelphia: Lea and Febiger, 1979:60-2.

4 McAlpine WA. Heart and coronary arteries. Berlin: Springer, 1975:9. 